
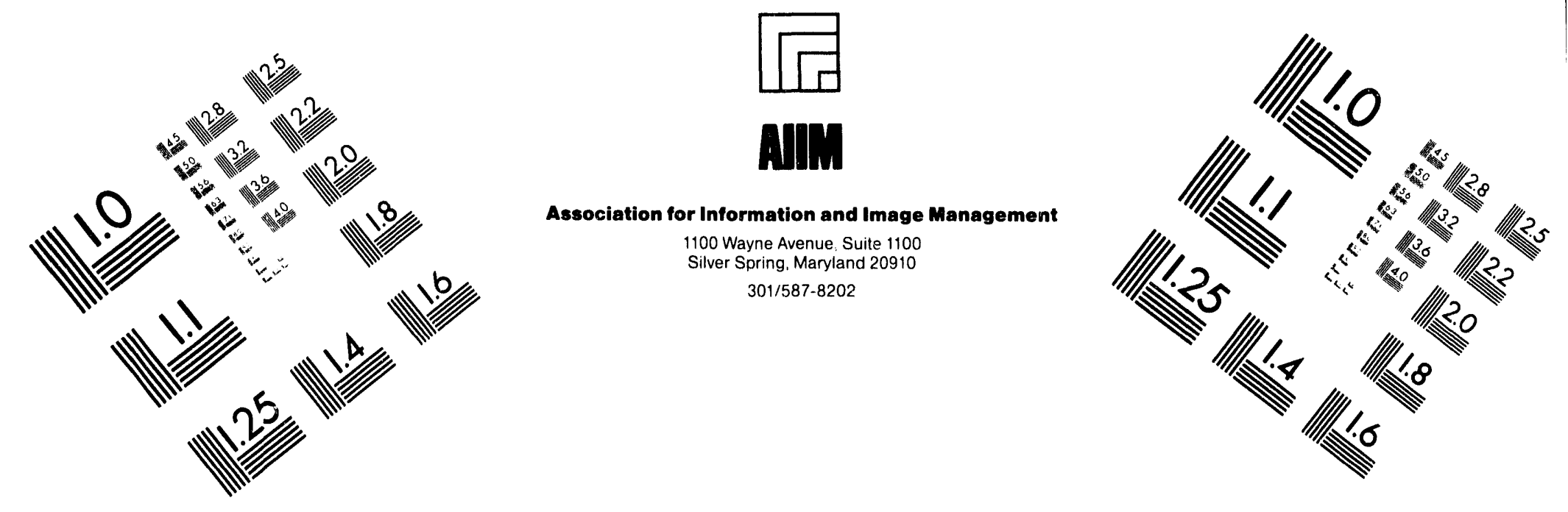

\title{
Centimeter
}

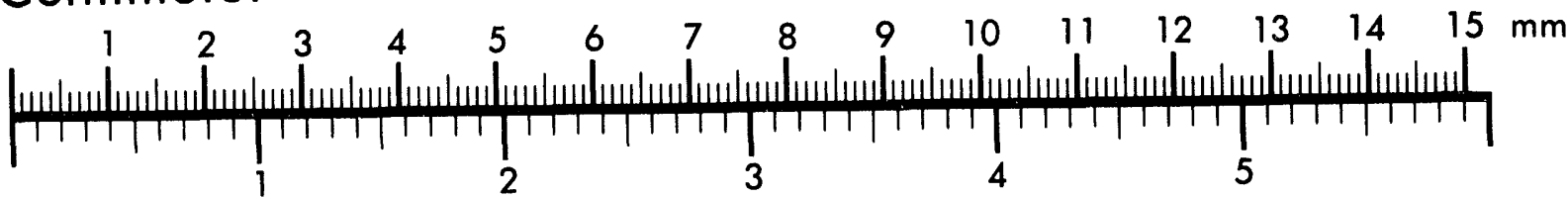
Inches
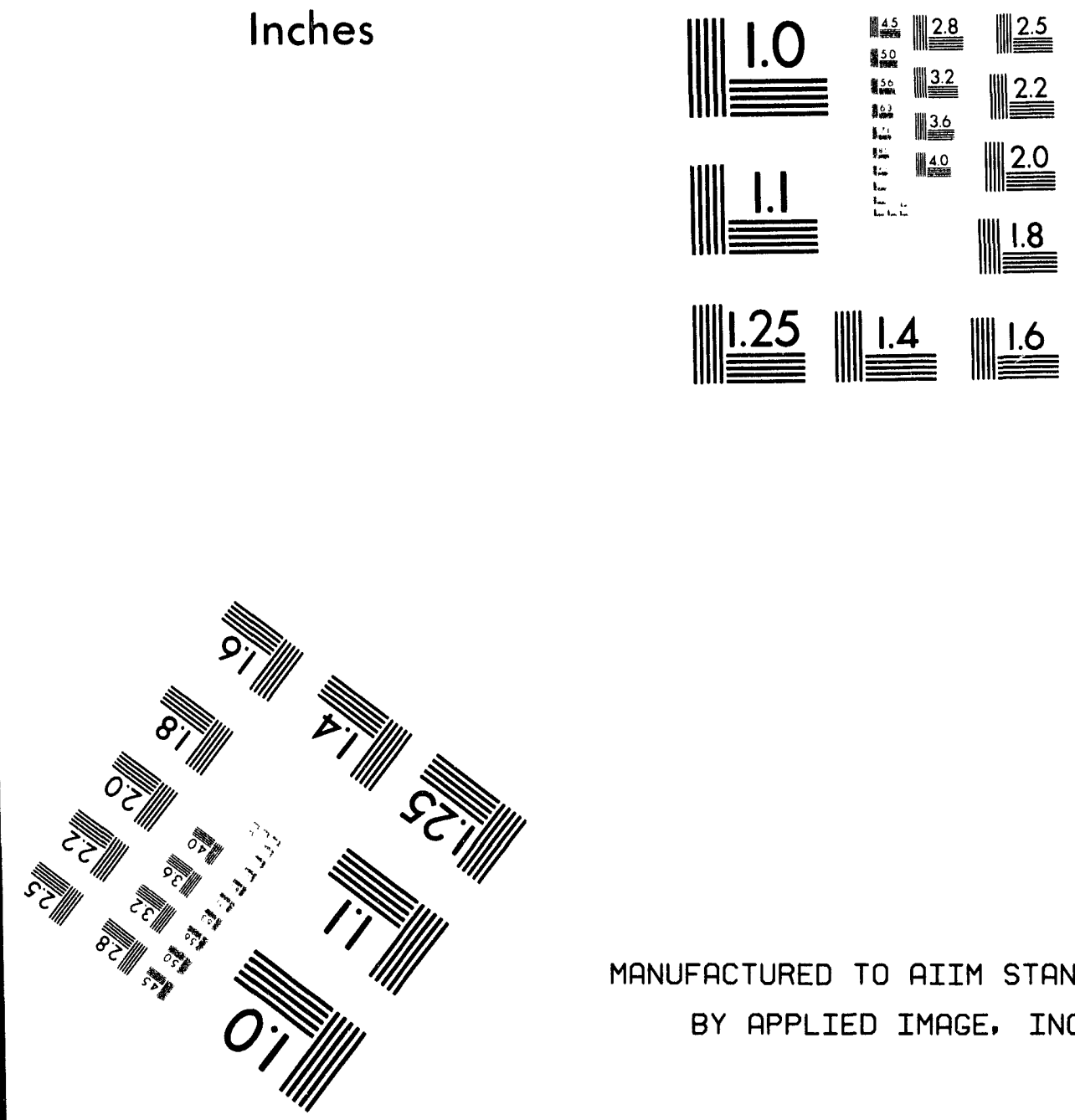

MANUFACTURED TO AIIM STANDARDS

BY APPLIED IMAGE, INC.

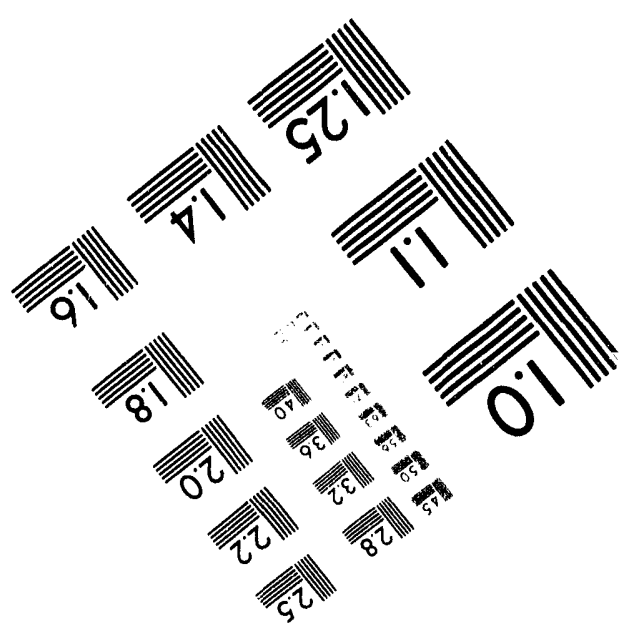



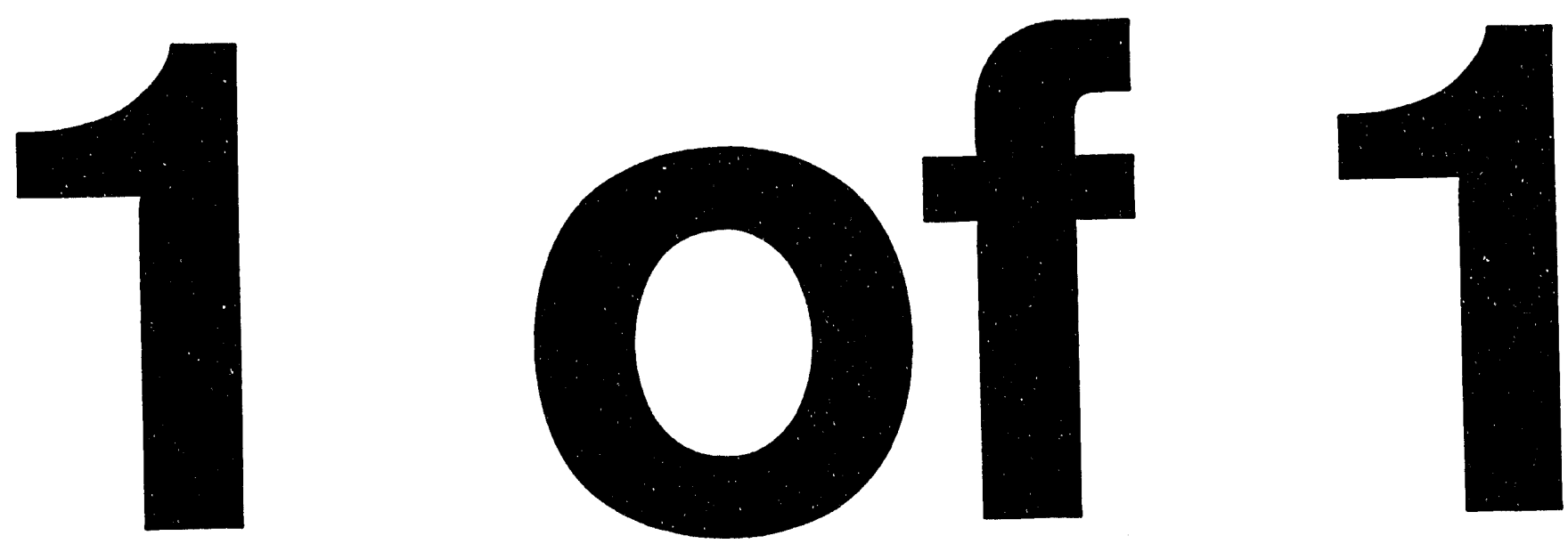
NUREG/CR-5830

PNL-7784

\section{Auxiliary Feedwater System Risk-Based Inspection Guide for the McGuire Nuclear Power Plant}

Manuscript Completed: April 1994

Date Published: May 1994

Prepared by

J. D. Bumgardner, R. C. Lloyd, N. E. Moffitt, B. F. Gore, T.V. Vo

Pacific Northwest Laboratory

Richland, WA 99352

Prepared for

Division of Systems Safety and Analysis

Office of Nuclear Reactor Regulation

U.S. Nuclear Regulatory Commission

Washington, DC 20555-0001

NRC FIN L1310 


\begin{abstract}
In a study sponsored by the U.S. Nuclear Regulatory Commission (NRC), Pacific Northwest Laboratory has developed and applied a methodology for deriving plant-specific risk-based inspection guidance for the auxiliary feedwater (AFW) system at pressurized water reactors that have not undergone probabilistic risk assessment (PRA). This methodology uses existing PRA results and plant operating experience information. Existing PRA-based inspection guidance information recently developed for the NRC for various plants was used to identify generic component failure modes. This information was then combined with plant-specific and industry-wide component information and failure data to : Jentify failure modes and failure mechanisms for the AFW system at the selected plants. McGuire was selected as one of a series of plants for study. The product of this effort is a prioritized listing of AFW failures which have occurred at the plant and at other PWRs. This listing is intended for use by NRC inspectors in the preparation of inspection plans addressing AFW risk-important components at the McGuire plant.
\end{abstract}




\section{Contents}

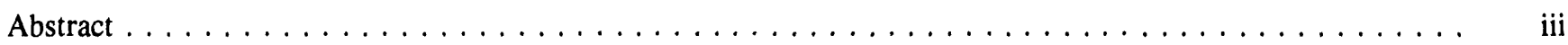

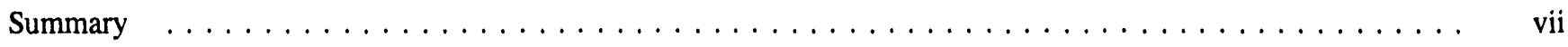

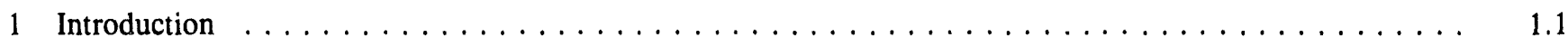

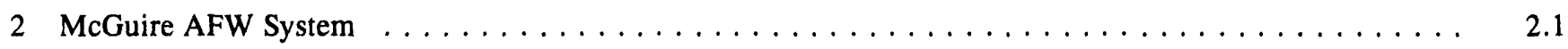

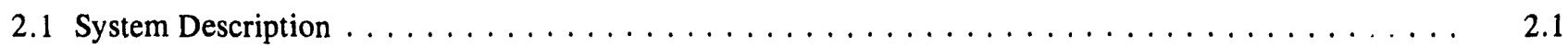

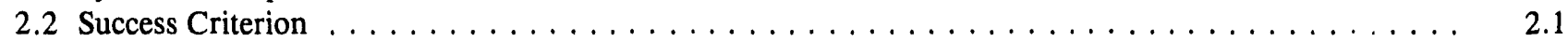

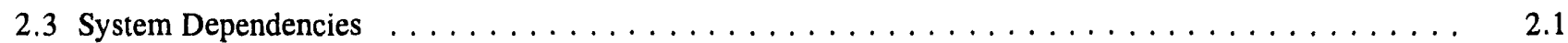

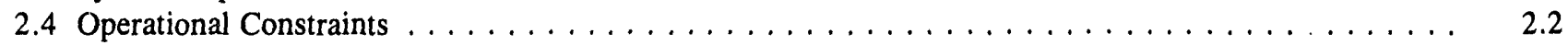

3 Inspection Guidance for The McGuire AFW System $\ldots \ldots \ldots \ldots \ldots$

3.1 Risk Important AFW Components and Failure Modes $\ldots \ldots \ldots \ldots$

3.1 .1 Multiple Pump Failures Due to Common Cause $\ldots \ldots \ldots \ldots \ldots$

3.1.2 Turbine Driven Pump Fails to Start or Run $\ldots \ldots \ldots \ldots \ldots$

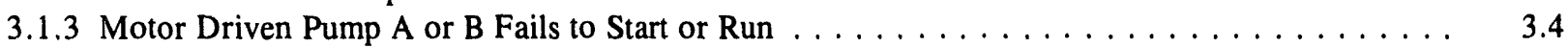

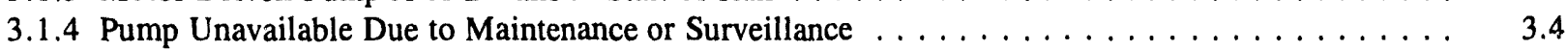

3.1 .5 Air Operated Flow Control Valves Fail Closed $\ldots \ldots \ldots \ldots \ldots$

3.1 .6 Motor Operated Isolation Valves Fail Closed $\ldots \ldots \ldots \ldots$

3.1 .7 Manual Suction or Discharge Valves Fail Closed $\ldots \ldots \ldots \ldots$

3.1.8 Leakage of Hot Feedwater Through Check Valves $\ldots \ldots \ldots \ldots$

3.2 Risk Important AFW System Walkdown Table $\ldots \ldots \ldots \ldots \ldots \ldots$

4 Generic Risk Insights From PRAs $\ldots \ldots \ldots \ldots \ldots \ldots$

4.1 Risk Important Accident Sequences Involving AFW System Failure $\ldots \ldots \ldots$

4.2 Risk Important Component Failure Modes $\ldots \ldots \ldots \ldots \ldots \ldots$

5 Failure Modes Determined from Operating Experience $\ldots \ldots \ldots \ldots \ldots$

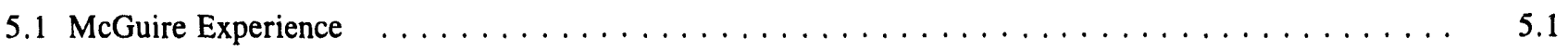

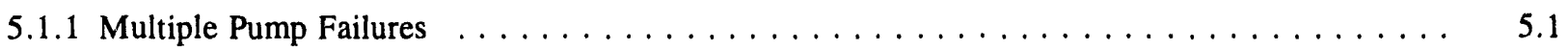

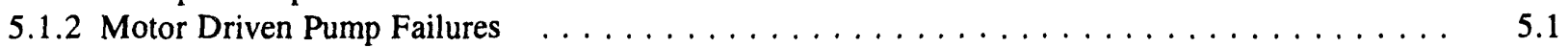

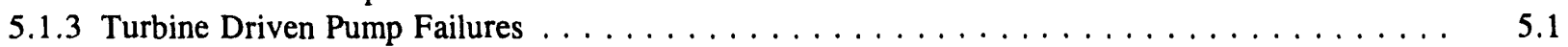

5.1 .4 Flow Control and Isolation Valve Failures $\ldots \ldots \ldots \ldots \ldots \ldots$

5.1 .5 Check Valve Failures $\ldots \ldots \ldots \ldots \ldots \ldots \ldots \ldots \ldots$

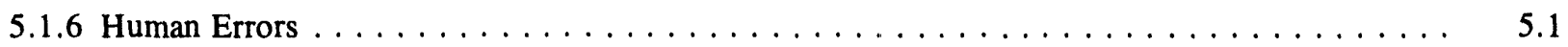




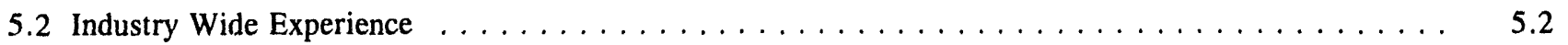

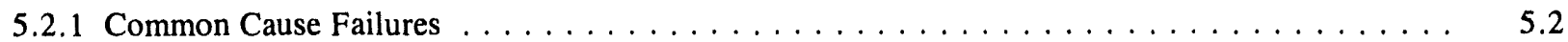

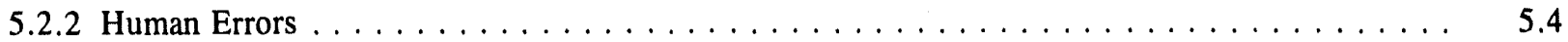

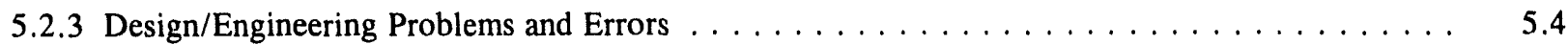

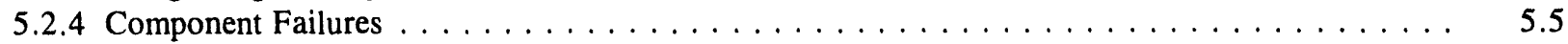

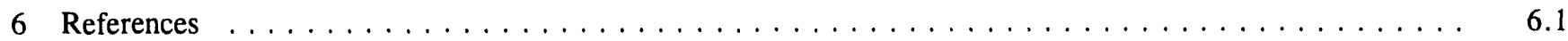




\section{Summary}

This document presents a compilation of auxiliary feedwater (AFW) system failure information which has been screened for risk significance in terms of failure frequency and degradation of system performance. It is a risk-pi.jittized listing of failure events and their causes that are significant enough to warrant consideration in inspection planning at the the McGuire plant. This information is presented to provide inspectors with increased resources for inspection planning at McGuire.

The risk importance of various component failure modes was identified by analysis of the results of probabilistic risk assessments (PRAs) for many pressurized water reactors (PWRs). However, the component failure categories identified in PRAs are rather broad, because the failure data used in the PRAs is an aggregate of many individuals failures having a variety of root causes. In order to help inspectors to focus on specific aspects of component operation, maintenance and design which might cause these failures, an extensive review of component failure information was performed to identify and rank the root causes of these component failures. Both McGuire and industry-wide failure information was analyzed. Failure causes were sorted on the basis of frequency of occurrence and seriousness of consequence, and categorized as common cause failures, human errors, design problems, or component failures.

This information is presented in the body of this document. Section 3.0 provide brief descriptions of these risk-important failure causes, and Section 5.0 presents more extensive discussions, with specific examples and references. The entries in the two sections are cross-referenced.

An abbreviated system walkdown table is presented in Section 3.2 which includes only components identified as risk important. This table lists the system lineup for normal, standby system operation.

This information permits an inspector to concentrate on components important to the preventisn of core damage. However, it is important to note that inspections should not focus exclusively on these com;ionents. Other components which perform essential functions, but which are not included because of high riliability or redundancy, must also be addressed to ensure that degradation does not increase their failure probabilities, and hence their risk importances. 


\section{Introduction}

This document is one of a series providing plant-specific inspection guidance for auxiliary feedwater (AFW) systems at pressurized water reactors (PWRs). This guidance is based on information from probabilistic risk assessments (PRAs) for similar PWRs, industry-wide operating experience with AFW systems, plant-specific AFW system descriptions, and plant-specific operating experience. It is not a detailed inspection plan, but rather a compilation of AFW system failure information which has been screened for risk significance in terms of failure frequency and degradation of system performance. The result is a risk-prioritized listing of failure events and the causes that are significant enough to warrant consideration in inspection planning at McGuire.

This inspection guidance is presented in Section 3.0, following a description of the McGuire AFW system in Section 2.0. Section 3.0 identifies the risk important system components by McGuire identification number, followed by brief descriptions of each of the various failure causes of that component. These include specific human errors, design deficiencies, and hardware failures. The discussions also identify where common cause failures have affected multiple, redundant components. These brief discussions identify specific aspects of system or component design, operation, maintenance, or testing for inspection by observation, records review, training observation, procedures review, or by observation of the implementation of procedures. An AFW system walkdown table identifying risk important components and their lineup for normal, standby system operation is also provided.
The remainder of the document describes and discusses the information used in compiling this inspection guidance. Section 4.0 describes the risk importance information which has been derived from PRAs and its sources. As review of that section will show, the failure events identified in PRAs are rather broad (e.g., pump fails to start or run, valve fails closed). Section 5.0 addresses the specific failure causes which have been combined under these broad events.

AFW system operating history was studied to identify the various specific failures which have been aggregated into the PRA failure events. Section 5.1 presents a summary of McGuire failure information, and Section 5.2 presents a review of industry-wide failure information. The industry-wide information was compiled from a variety of NRC sources, including AEOD analyses and reports, information notices, inspection and enforcement bulletins, and generic letters, and from a variety of INPO reports as well. Some Licensee Event Reports and NPRDS event descriptions were also reviewed. Finally, information was included from reports of NRC-sponsored studies of the effects of plant aging, which include quantitative analyses of reported AFW system failures. This industrywide information was then combined with the plantspecific failure information to identify the various root causes of the broad failure events used in PRAs, which are identified in Section 3.0. 


\section{McGuire AFW System}

This section presents an overview of the McGuire AFW system, including a simplified schematic system diagram. In addition, the system success criterion, system dependencies, and administrative operational constraints are also presented.

\subsection{System Description}

The AFW system provides feedwater to the steam generators (SG) to allow secondary-side heat removal from the primary system when main feedwater is unavailable. The system is capable of functioning for extended periods, which allows time to restore main feedwater flow or to proceed with an orderly cooldown of the plant to where the residual heat removal (RHR) system can remove decay heat. A simplified schematic diagram of the McGuire AFW system is shown in Figure 2.1.

The preferred source of AFW pump suction is from the upper surge tank (UST), with alternate suction sources from the condensate storage tank (CST) and the condenser hotwell. A common header supplies water to both the motor-driven and turbine-driven pumps through a check valve and a normally open motor controlled isolation valve. Two additional back-up sources of water for the AFW pumps are provided from the nuclear service water system (RN) and the condenser circulating water system (RC). Power, control, and instrumentation associated with each train are independent from each other. Steam for the turbine driven pump is supplied through SA-48 and SA-49 from steam generators $B$ and $C$, from a point upstream of the main steam isolation valves. Each AFW pump is equipped with a recirculation flow system which prevents pump deadheading.

The system is designed to start up and establish flow automatically. All pumps start on receipt of a steam generator low-low level signal. (The motor-driven pumps start on low-low level in one SG, whereas, two SG lowlow level signals are required for a turbine-driven pump start.) The motor-driven (MD) pumps start for the following conditions: safety injection, blackout, trip of both main feedwater pumps, and AMSAC (ATWS Mitigation
System Actuation Circuitry). In addition, the single turbine-driven (TD) pump starts on a station blackout condition.

The discharges of the motor-driven pumps are normally aligned so that the A pump supplies the A and B steam generators and the $B$ pump supplies the $C$ and $D$ steam generators. Cross-connect valves are provided to allow feeding of any steam generator from either pump. The cross-connect valves are locked shut and administratively controlled. The turbine-driven pump supplies water to all four steam generators, but through separate lines. Steam generator inlet isolation valves are locked open manual valves and the discharge isolation valves are motor operated. Flow control valves in each of the eight feedwater lines are pneumatic. Each line also contains multiple check valves to prevent leakage from the feedwater lines.

The Condensate Storage System (CSS), which is comprised of the CST, Upper Surge Tank and Condenser Hotwell, provides the normal suction sources for the AFW system and is required to store sufficient water to maintain the reactor coolant system (RCS) at hot standby for two hours followed by a cooldown to the point where RHR system can be placed in service. All tank connections except those required for instrumentation, auxiliary feedwater pump suction, and tank drainage are located above this minimum level.

\subsection{Success Criterion}

System success requires the operation of at least one pump supplying rated flow to two steam generators.

\subsection{System Dependencies}

The AFW system depends on AC power for motor-driven pumps and motor-controlled isolation valves, $\mathrm{DC}$ power for control power to pumps, valves, and automatic actuation signals, and instrument air for AFW flow control valves. In addition, the turbine-driven pump also requires steam availability. 


\subsection{Operational Constraints}

When the reactor is critical the McGuire Technical Specifications require that all three AFW pumps and associated flow paths are operable with each motor-driven pump powered from a different emergency bus. If one AFW pump becomes inoperable, it must be restored to operable status within 72 hours or the plant must be shut down to hot standby within the next six hours. If two AFW pumps are inoperable, the plant must be shut down to hot standby within six hours and in Hot Shutdown within the following six hours. With three AFW pumps inoperable, corrective action to restore at least one pump to operable status must be initiated immediately, and the plant must be shut down to hot standby within six hours and in Hot Shutdown within the following six hours.

The operability of the AFW system ensures that the reactor coolant system can be cooled down to less than 350 degrees from normal operating conditions in the event of a total loss of offsite power. 


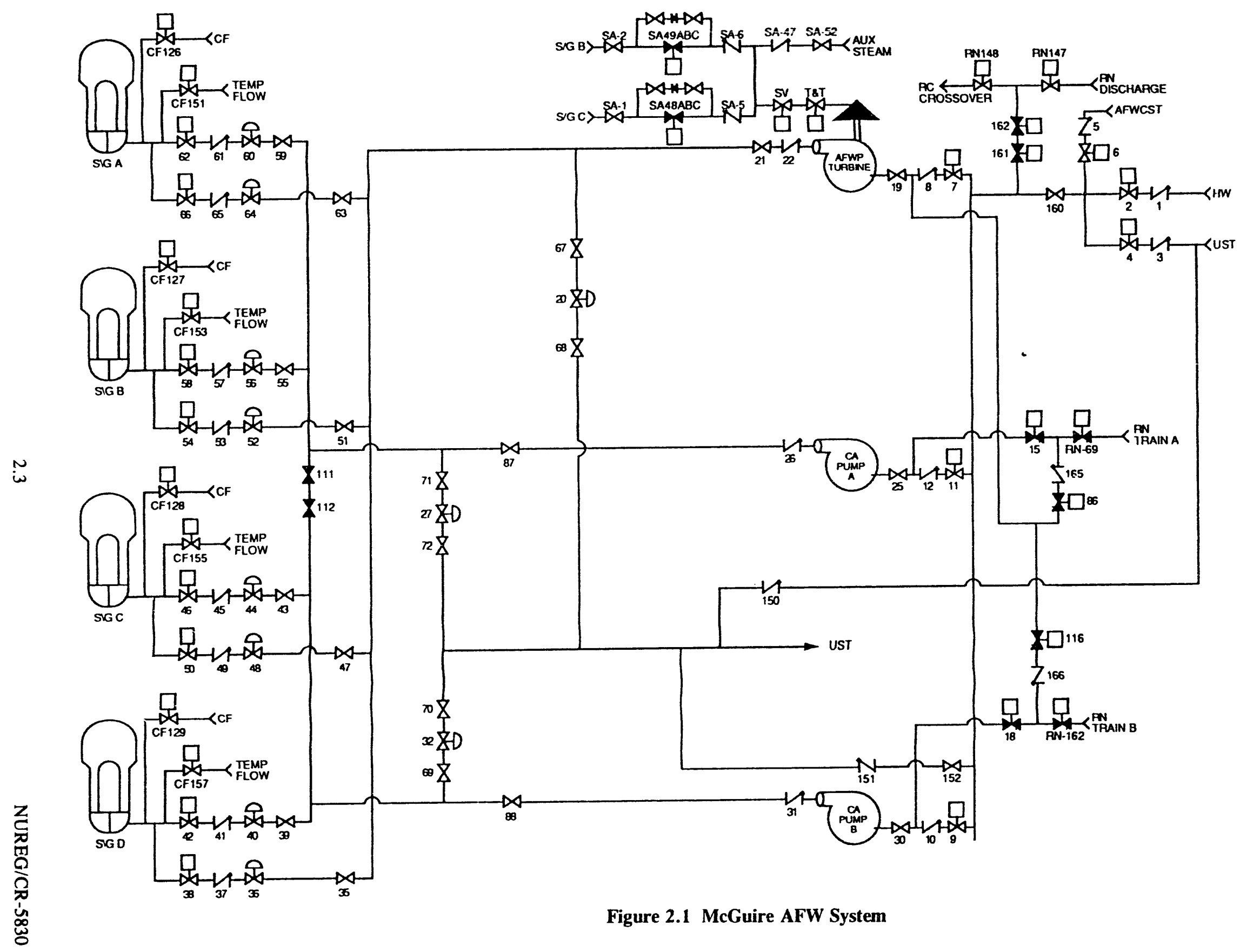




\section{Inspection Guidance for the McGuire AFW System}

In this section the risk important components of the McGuire AFW system are identified, and the important failure modes for these components are briefly described. These failure modes include specific human errors, design deficiencies, and types of hardware failures which have been observed to occur for these components, both at McGuire and at PWRs throughout the nuclear industry. The discussions also identify where common cause failures have affected multiple, redundant components. These brief discussions identify specific aspects of system or component design, operation, maintenance, or testing for inspection activities. These activities include; observation, records review, training observation, procedures review, or by observation of the implementation of procedures.

Table 3.1 is an abbreviated AFW system walkdown table which identifies risk-important components. This table lists the system lineup for normal (standby) system operation. Inspection of the identified components addresses essentially all of the risk associated with AFW system operation.

\subsection{Risk Important AFW Components and Failure Modes}

Common cause failures of multiple pumps are the most risk-important failure modes of AFW system components. These are followed in importance by single pump failures, level control valve failures, and individual check valve leakage failures.

The following sections address each of these failure modes, in decreasing order of risk-importance. They present the important root causes of these component failure modes which have been distilled from historical records. Each item is keyed to discussions in Section 5.2 where additional information on historical events is presented.

\subsubsection{Multiple Pump Failures Due to Common Cause}

The following listing summarizes the most important multiple-pump failure modes identified in Section 5.2.1, Common Cause Failures, and each item is keyed to entries in that section.

- Incorrect operator intervention into automatic system functioning, including improper manual starting and securing of pumps, has caused failure of all pumps, including overspeed trip on startup, and inability to restart prematurely secured pumps. $\mathrm{CC} 1$. At McGuire incorrect operator interpretation of control panel information during a loss of control room test caused difficulty in control of the AFW system which resulted in an abnormally fast cool down.

Inspection Suggestion - Observe Abnormal and Emergency Operating Procedure (AOP/EOP) simulator training exercises to verify that the operators comply with procedures during observed evolutions. Observe surveillance testing on the AFW system to verify it is in strict compliance with the surveillance test procedure.

- Valve mispositioning has caused failure of all pumps. Pump suction, steam supply, and instrument isolation valves have been involved. CC2 . At McGuire, the motor-driven AFW pumps started on a false signal. The operator actuated valves incorrectly in the recovery process.

Inspection Suggestion - Verify that the system valve alignment, air operated valve control and valve actuating air pressures are correct using 3.1 Walkdown Table, the system operating procedures, and 
Inspection Guidance

operator rounds logsheet. Rev iew surveillance procedures that alter the standby alignment of the AFW system. Ensure that an adequate return to normal section exists.

- Steam binding has caused failure of multiple pumps. This resulted from leakage of hot feedwater past check valves into a common discharge header, with several valves involved including a motor-operated discharge valve. CC10. Multiple-pump steam binding has also resulted from improper valve lineups, and from running a pump deadheaded. CC3.

Inspection Suggestion - Verify that the pump discharge temperature is within the limits specified on the operator rounds logsheet. Ensure any instruments used to verify the temperature by the utility are of an appropriate range and included in a calibration program. Verify affected pumps have been vented in accordance with procedures to ensure steam binding has not occurred. Verify that a maintenance work request has been written to repair leaking check valves.

- Pump control circuit deficiencies or design modification errors have caused failures of multiple pumps to auto start, spurious pump trips during operation, and failures to restart after pump shutdown. CC4. At McGuire, similar incidences have occurred. Motor-driven pump electrical leads were shorted to the turbine-driven pump electrical circuitry causing incorrect operation of that pump. Incorrect set points and control circuit calibrations have also prevented proper operation of multiple pumps. CC5.

Inspection Suggestion - Review design change implementation documents for the post maintenance testing required prior to returning the equipment to service. Ensure the testing verifies that all potentially impacted functions operate correctly, and includes repeating any plant start-up or hot functional testing that may be affected by the design change.
- Loss of a vital power bus has failed both the turbine-driven and one motor-driven pump due to loss of control power to steam admission valves or to turbine controls, and to motor controls powered from the same bus. CC6.

Inspection Suggestion - The material condition of the electrical equipment is an indicator of probable reliability. Review the Preventative Maintenance (PM) records to Ensure the equipment is maintained on an appropriate frequency for the environment it is in and that the PM's are actually being performed as required by the program. Review the outstanding Corrective Maintenance records to Ensure the deficiencies found on the equipment are promptly corrected.

- Simultaneous startup of multiple pumps has caused oscillations of pump suction pressure causing multiple-pump trips on low suction pressure, despite the existerce of adequate static net positive suction head (NPSH). CC7. Design reviews have identified inadequately sized suction piping which could have yielded insufficient NPSH to support operation of more than one pump. $\mathrm{CC} 8$.

Inspection Suggestion - Ensure that plant conditions which could result in the blockage or degradation of the suction flow path are addressed by system maintenance and test procedures. Examples include, if the AFW system has an emergency source from a water system with the potential for bio-fouling, then the system should be periodically treated to prevent buildup and routinely tested to Ensure an adequate flow can be achieveu to support operation of all pumps, or inspected to Ensure that bio-fouling is not occurring. Design changes that affect the suction flow path should repeat testing that verified an adequate suction source for simultaneous operation of all pumps. Verify that testing has, at sometime, demonstrated simultaneous operation of all pumps. Verify that surveillances adequately test all aspects of the system design functions, for example, demonstrate that the AFW pumps will trip on low suction pressure. 


\subsubsection{Turbine Driven Pump Fails to Start or Run}

- Improperly adjusted and inadequately maintained turbine governors have caused pump failures. HE2. Problems include worn or loosened nuts, set screws, linkages or cable connections, oil leaks and/or contamination, and electrical failures of resistors, transistors, diodes and circuit cards, and erroneous grounds and connections. CF5. Improperly maintained governors where oil level was found to be low have occurred at McGuire. Also, accidently shorted electrical leads to the turbine-driven pump control circuit have caused failure of that pump.

Inspection Suggestion - Review PM records to Ensure the governor oil is being replaced within the designated frequency. During plant walkdowns carefully inspect the governor and linkages for loose fasteners, leaks, ana unsecured or degraded conduit. Review vendor manuals to ensure PM procedures are performed according to manufacturer's recommendations and good maintenance practices.

- Terry turbines with Woodward Model EG governors have been found to overspeed trip if full steam flow is allowed on startup. Sensitivity can be reduced if a startup steam bypass valve is sequenced to open first. DE1.

- Turbines with Woodward Model PG-PL governors have tripped on overspeed when restarted shortly after shutdown, unless an operator has locally exercised the speed setting knob to drain oil from the governor speed setting cylinder (per procedure). Automatic oil dump valves are now available through Terry. DE4.

Inspection Suggestion - Observe the operation of the turbine driven Aux Feed pump and Ensure that the governor is reset as directed in OP/1/A/6250/02, by rotating the speed control knob fully in the counter clockwise direction, then fully in the clockwise direction. Ensure the turbine is not coasting over, which can result in refill of the speed setting cylinder.

- Condensate slugs in steam lines have caused turbine overspeed trip on startup. Tests repeated right after such a trip may fail to indicate the problem due to warming and clearing of the steam lines. Surveillance should exercise all steam supply connections. DE2.

Inspection Suggestion - Verify that the steam traps are valved in on the steam supply line. For steam traps that are on a pressurized portion of the steam line, check the steam trap temperature (if unlagged) to Ensure it is warmer than ambient (otherwise it may be stuck or have a plugged line). If the steam trap discharge is visible, Ensure there is evidence of liquid discharge.

- Trip and throttle valve (TTV) problems which have failed the turbine driven pump include physically bumping it, failure to reset it following testing, and failures to verify control room indication of reset. HE2. Whether either the overspeed trip or TTV trip can be reset without resetting the other, indication in the control room of TTV position, and unambiguous local indication of an overspeed trip affect the likelihood of these errors. DE3. At McGuire, a steam supply valve was slow to operate due to a replaced orifice being too small.

Inspection Suggestion - Carefully inspect the TTV overspeed trip linkage and Ensure it is reset and in good physical condition. Ensure that there is a good steam isolation to the turbine, otherwise continued turbine high temperature can result in degradation of the oil in the turbine, interfering with proper overspeed trip operation. Review training procedures to ensure operator training on resetting the TTV is current.

- Low lubrication oil pressure resulting from heatup because of previous operation has prevented pump restart from failure to satisfy the protective interlock. DE5.

Inspection Suggestion - Low oil pressure is a trip that is in service at all times for the turbine driven AFW pump. Normally the low oil pressure occurs at approximately $1400 \mathrm{rpm}$ and serves to protect the pump from low RPM operation. However, low oil pressure due to a plugged filter will also cause a trip. Review 
Inspection Guidance

PM records toEnsure the filter is replaced on the designated frequency.

\subsubsection{Motor Driven Pump A or B Fails to Start or Run}

- Control circuits used for automatic and manual pump starting are an important cause of motor driven pump failures, as are circuit breaker failures. CF7.

Inspection Suggestion - Review corrective maintenance records when control circuit problems occur to determine if a trend exists. Every time a breaker is racked in a PMT should be performed to start the pump, assuring no control circuit problems have occurred as a result of the manipulation of the breaker. (Control circuit stabs have to make up upon racking the breaker, and cell switch damage can occur upon removal and reinstallation of the breaker.)

- Mispositioning of handswitches and procedural deficiencies have prevented automatic pump start. HE3. Mispositioning of handswitches has occurred at McGuire.

Inspection Suggestion - Confirm switch position using Table 3.1. Review administrative procedures concerning documentation of procedural deficiencies. Ensure operator training on procedural changes is current.

\subsubsection{Pump Unavailable Due to Maintenance or Surveillance}

- Both scheduled and unscheduled maintenance remove pumps from operability. Surveillance requires operation with an altered line-up, although a pump train may not be declared inoperable during testing. Prompt scheduling and performance of maintenance and surveillance minimize this unavailability.

Inspection Suggestion - Review the time the AFW system and components are inoperable. Ensure all maintenance is being performed that can be performed during a single outage time frame, avoiding multiple equipment outages. The maintenance should be scheduled before the routine surveillance test, so credit can be taken for both post maintenance testing and surveillance testing, avoiding excessive testing. Review surveillance schedule for frequency and adequacy to verify system operability requirements per Technical Specifications.

\subsubsection{Air Operated Flow Control Valves Fail Closed}

TD Pump Train: CA-36, 48, 52, 64

MD Pump Train: CA-40,44, 56,60

These normally closed air operated valves (AOVs) control flow to the steam generators. They fail open on loss of Instrument Air.

- Control circuit problems have been a primary cause of failures, both at McGuire and elsewhere. CF9. Valve failures have resulted from blown fuses, failure of control components (such as current/pneumatic convertors), broken or dirty contacts, misaligned or broken limit switches, control power loss, and calibration problems.

Inspection Suggestion - Check for control air system alignment and air leaks during plant walkdowns. (Regulators may have a small amount of external bleed to maintain downstream pressure.) Check for cleanliness and physical condition of visible circuit elements. Review valve stroke time surveillance for adverse trends, especially those valves on reduced testing frequency. Review air system surveillances to verify that moisture content of air is within established limits.

- Out-of-adjustment electrical flow controllers have caused improper valve operation, affecting multiple trains of AFW. CC12. McGuire has experienced problems in individual trains.

Inspection Suggestion - Review PM frequency and records, only upon a trend of failure of the controllers.

- Leakage of hot feedwater through check valves has caused thermal binding of flow control MOVs. AOVs may be similarly susceptible. CF2. 
Inspection Suggestion - Covered by 3.1.1 bullet 3 .

- Inadequate air pressure regulation at McGuire has resulted in control valve failure to operate and degraded operation due to low air pressure output from the compressor, a plugged air line and a broken air line.

Inspection Suggestion - Covered by 3.1.5 bullet 1 .

- Multiple flow control valves have been plugged by clams when suction switched automatically to an alternate, untreated source. CC9.

Inspection Suggestion - Covered by 3.1.1 bullet 6 .

\subsubsection{Motor Operated Isolation Valves Fail Closed}

MD Pump Discharge Isolation: CA-42B, 46B, 58A, 62A

TD Pump Discharge Isolation: CA-38A, 50A, 54B, 66B

Nuclear Service Water Suction Isolation: 15A, 116B, 18B, 86B

CSS Suction Isolation: CA-2, 4,6,7AC, 9B, 11A MFW Tempering Flow Isolation: CF-151, 153, 155 , $\underline{157}$

These MOVs isolate flow to the steam generators and provide AFW pump suction isolation. The discharge isolation valves and CST suction valves are normally open and the nuclear service water suction valves are normally closed. They all fail as-is on loss of power.

- Common cause failure of MOVs has occurred at McGuire and elsewhere, from failure to use electrical signature tracing equipment to determine proper settings of torque switch and torque switch bypass switches. Failure to calibrate switch settings for high torques necessary under design basis accident conditions has also been involved. $\mathrm{CC} 11$.

Inspection Suggestion - Review the MOV test records to Ensure the testing and settings are based on dynamic system conditions. Overtorquing of the valve operator can result in valve damage such as cracking of the seat or disc. Review the program to Ensure overtorquing is identified and corrective actions are taken to aEnsure valve operability following an overtorque condition. Review the program to aEnsure EQ seals are renewed as required during the restoration from testing to maintain the EQ rating of the MOV.

- Valve motors have been failed due to lack of, or improper sizing or use, of thermal overload protective devices. Bypassing and oversizing should be based on proper engineering for design basis conditions. CF4.

Inspection Suggestion - Review the administrative controls for documenting and changing the settings of thermal overload protective devices. Ensure the information is available to the maintenance planners.

- Out-of-adjustment electrical flow controllers have caused improper discharge valve operation, affecting multiple trains of AFW. CC12.

Inspection Suggestion - Review PM frequency and records, only upon a trend of failure of the controllers.

- Grease trapped in the torque switch spring pack of the operators of MOVs has caused motor burnout or thermal overload trip by preventing torque switch actuation. CF8.

Inspection Suggestion - Review this only if the MOV testing program reveals deficiencies in this area.

- Manually reversing the direction of motion of operating MOVs has overloaded the motor circuit. Operating procedures should provide cautions, and circuit designs may prevent reversal before each stroke is finished. DE7.

Inspection Suggestion - Review operating procedures and operator performance of valve positioning.

- Space heaters designed for preoperation storage have been found wired in parallel with valve motors which had not been environmentally qualified with them present. DE7. 
Inspection Suggestion - Spot check MOV's during MOV testing to Ensure the space heaters are physically removed or disconnected.

\subsubsection{Manual Suction or Discharge Valves Fail Closed}

TD Pump Train: CA-19;21; 63, 51, 47,35 MD Pump Trains A; B: CA-25, 30;87, 88; 59, 55 , 43,39

These manual valves are normally locked open. For each train, closure of the first valves would block pump suction, closure of the second valves would block pump discharge and closure of the third set of valves would block discharge to steam generators $A, B, C$, and $D$ respectively.

- Valve mispositioning has resulted in failures of multiple trains of AFW. CC2. It has also been the dominant cause of problems identified during operational readiness inspections. HE1. Events have occurred most often during maintenance, calibration, or system modifications. Important causes of mispositioning include:

- Failure to provide complete, clear, and specific procedures for tasks and system restoration

- Failure to promptly revise and validate procedures, training, and diagrams following system modifications

- Failure to complete all steps in a procedure

- Failure to adequately review uncompleted procedural steps after task completion

- Failure to verify support functions after restoration

- Failure to adhere scrupulously to administrative procedures regarding tagging, control and tracking of valve operations

- Failure to log the manipulation of sealed valves
- Failure to follow good practices of written task assignment and feedback of task completion information

- Failure to provide easily read system drawings, legible valve labels corresponding to drawings and procedures, and labeled indications of local valve position

Inspection Suggestion - Review the administrative controls that relate to valve positioning and sealing, system restoration following maintenance, valve labeling, system drawing updating, and procedure revision, for proper implementation.

\subsubsection{Leakage of Hot Feedwater Through Check Valves:}

MD Pump Trains A; B: CA-61, 57; CA-45, 41 TD Pump Train: CA-65, 53, 49, 37

- Leakage of hot feedwater through several check valves in series has caused steam binding of multiple pumps. Leakage through a closed level control valve in series with check valves has also occurred, as would be required for leakage to reach the motor driven or turbine driven pumps. $\mathrm{CC} 10$

Inspection Suggestion - Covered by 3.1 .1 bullet 3 .

- Slow leakage past the final check valve of a series may not force upstream check valves closed, allowing leakage past each of them in turn. Piping orientation and valve design are important factors in achieving true series protection. CF1.

Inspection Suggestion - Covered by 3.1.1 bullet 3 .

- The turbine-driven pump at McGuire experienced reverse rotation and a pressurized suction which was attributed to a leaky swing check valve.

Inspection Suggestion - Covered by 3.1.1 bullet 3 . 


\subsection{Risk Important AFW System Walkdown Table}

Table 3.1 presents an AFW system walkdown table including only components identified as risk important. This information allows inspectors to concentrate their efforts on components important to prevention of core damage. However, it is essential to note that inspections should not focus exclusively on these components. Other components which perform essential functions, must also be addressed to ensure that their risk importances are not increased. Examples include the (open) steam lead stop check valves and an adequate water level in the CST. 
Inspection Guidance

Table 3.1 Risk Importance AFW System Walkdown Table

\begin{tabular}{|c|c|c|c|}
\hline Component \# & Component Name & Required Location & $\begin{array}{l}\text { Actual } \\
\text { Positio }\end{array}$ \\
\hline & Electrical & & \\
\hline A & Motor Driven Pump & $\begin{array}{l}\text { Racked In/ } \\
\text { Closed }\end{array}$ & - \\
\hline \multirow[t]{2}{*}{ B } & Motor Driven Pump & Racked In/ & - \\
\hline & $\underline{\text { Valve }}$ & & \\
\hline CA-2 & CA Pump Suct From HTWL ISOL & Open & {[} \\
\hline CA-4 & CA Pump Suct From UST & Open & \\
\hline CA-6 & CA Pump Suct From AFW CST & Open & \\
\hline CA-7 & TD CA Pump Norm Suct ISOL & Open & \\
\hline CA-9 & CA Pump B Norm Suct ISOL & Open & \\
\hline CA-11 & CA Pump A Norm Suct ISOL & Open & \\
\hline CA-15 & CA Pump A Suct From RN ISOL & Auto/Closed & \\
\hline CA-18 & CA Pump B Suct From RN ISOL & Auto/Closed & \\
\hline CA-116 & TD CA Pump Suct From RN HDR B & Auto/Closed & \\
\hline CA-86 & TD CA Pump Suct From RN HDR A & Auto/Closed & \\
\hline CA-161 & Aux FDWP Suct HDR RN Supply ISOL & Closed & \\
\hline CA-162 & Aux FDWP Suct HDR RN Supply ISOL & Closed & \\
\hline CA-19 & TD CA Suct ISOL & Locked Open & \\
\hline CA-25 & CA Pump A Suct ISOL & Locked Open & \\
\hline CA-30 & CA Pump B Suct ISOL & Locked Open & \\
\hline CA-67 & TD CA Pump to UST Dome Throttle & Open & \\
\hline CA-68 & TD CA Pump to UST Dome ISOL & Open & \\
\hline CA-20 & TD CA Pump Throttle to UST Dome & Open & \\
\hline CA-71 & CA Pump A to UST Dome Throttle & Open & - \\
\hline CA-72 & CA Pump A to UST Dome ISOL & Open & \\
\hline CA-27 & CA Pump A Throttle to UST Dome & Open & - \\
\hline CA-69 & CA Pump B to UST Dome Throttle & Open & {[} \\
\hline
\end{tabular}


Table 3.1 Risk Importance AFW System Walkdown Table

\begin{tabular}{|c|c|c|c|}
\hline Component \# & Component Name & Required Location & $\begin{array}{l}\text { Actual } \\
\text { Position }\end{array}$ \\
\hline CA-70 & CA Pump B to UST Dome ISOL & Open & - \\
\hline CA-32 & CA Pump B Throttle to UST Dome & Open & L \\
\hline CA-21 & TD CA Pump Disch to S/G ISOL & Locked Open & \\
\hline CA-87 & CA Pump A Disch to S/G ISOL & Locked Open & \\
\hline CA-88 & CA Pump B Disch to S/G ISOL & Locked Open & - \\
\hline CA-35 & $\begin{array}{l}\text { TD CA Pump Disch to S/G 1D } \\
\text { Control Valve Inlet ISOL }\end{array}$ & Locked Open & \\
\hline CA-47 & $\begin{array}{l}\text { TD CA Pump Disch to S/G 1C } \\
\text { Control Valve Inlet ISOL }\end{array}$ & Locked Open & \\
\hline CA-51 & $\begin{array}{l}\text { TD CA Pump Disch to S/G 1B } \\
\text { Control Valve Inlet ISOL }\end{array}$ & Locked Open & \\
\hline CA-63 & $\begin{array}{l}\text { TD CA Pump Disch to S/G 1A } \\
\text { Control Inlet ISOL }\end{array}$ & Locked Open & \\
\hline CA-55 & $\begin{array}{l}\text { CA Pump A Disch to S/G 1B } \\
\text { Control Valve Inlet ISOL }\end{array}$ & Locked Open & \\
\hline CA-59 & $\begin{array}{l}\text { CA Pump A Disch to S/G 1A } \\
\text { Control Valve Inlet ISOL }\end{array}$ & Locked Open & \\
\hline CA-39 & $\begin{array}{l}\text { CA Pump B Disch to S/G 1D } \\
\text { Control Valve Inlet ISOL }\end{array}$ & Locked Open & \\
\hline CA-43 & $\begin{array}{l}\text { CA Pump B Disch to S/G 1C } \\
\text { Control Valve Inlet ISOL }\end{array}$ & Locked Open & \\
\hline CA-111 & $\begin{array}{l}\text { CA Pump A \& B Disch X-Over to } \\
\text { S/G ISOL }\end{array}$ & Locked Closed & \\
\hline CA-112 & $\begin{array}{l}\text { CA Pump A \& B Disch X-Over to } \\
\text { S/G ISOL }\end{array}$ & Locked Closed & \\
\hline CA-40 & CA Pump B Flow to S/G D & Open & - \\
\hline CA-44 & CA Pump B Flow to S/G C & Open & - \\
\hline CA-56 & CA Pump A Flow to S/G B & Open & - \\
\hline CA-60 & CA Pump A Flow to S/G A & Open & - \\
\hline CA-36 & TD CA Pump Flow to S/G D & Open & - \\
\hline CA-48 & TD CA Pump Flow to S/G C & Open & - \\
\hline
\end{tabular}


Table 3.1 Risk Importance AFW System Walkdown Table

\begin{tabular}{|c|c|c|c|}
\hline Component \# & Component Name & Required Location & $\begin{array}{l}\text { Actual } \\
\text { Position }\end{array}$ \\
\hline CA-52 & TD CA Pump Flow to S/G B & Open & - \\
\hline CA-64 & TD CA Pump Flow to S/G A & Open & $\underline{-}$ \\
\hline CA-62A & CA Pump A Disch to S/G A ISOL & Open & - \\
\hline CA-58A & CA Pump A Disch to S/G B ISOL & Open & {[} \\
\hline $\mathrm{CA}-46 \mathrm{~B}$ & CA Pump B Disch to S/G C ISOL & Open & {[} \\
\hline CA-42B & CA Pump B Disch to S/G D ISOL & Open & - \\
\hline CA-38B & TD CA Pump Disch to S/G D ISOL & Open & - \\
\hline CA-50B & TD CA Pump Disch to S/G C ISOL & Open & - \\
\hline CA-54A & TD CA Pump Disch to S/G B ISOL & Open & \\
\hline CA-66A & TD CA Pump Disch to S/G A ISOL & Open & \\
\hline CF-151 & S/G A CA Nozz Tempering ISOL & Open & 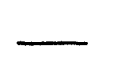 \\
\hline CF-153 & S/G B CA Nozz Tempering ISOL & Open & - \\
\hline CF-155 & S/G C CA Nozz Tempering ISOL & Open & \\
\hline CF-157 & S/G D CA Nozz Tempering ISOL & Open & - \\
\hline SA-5 & S/G C SM to TD CA Pump Stop Check & Open & - \\
\hline SA-6 & S/G B SM to TD CA Pump Stop Check & Open & - \\
\hline SA-49AB & S/G B SM to TD CA Pump ISOL & Closed & - \\
\hline SA-48ABC & S/G C SM to TD CA Pump ISOL & Closed & - \\
\hline SA-1 & S/G C SM to TD CA Pump & Locked Open & - \\
\hline \multirow[t]{2}{*}{ SA-2 } & S/G B SM to TD CA Pump & Locked Open & - \\
\hline & CAPT Trip and Throttle Valve & Open & - \\
\hline CA-8 & Piping Upstream of Check Valve & Cool & - \\
\hline CA-10 & Piping Upstream of Check Valve & Cool & - \\
\hline CA-12 & Piping Upstream of Check Valve & Cool & - \\
\hline CA-37 & Piping Upstream of Check Valve & Cool & - \\
\hline CA-41 & Piping Upstream of Check Valve & Cool & - \\
\hline CA-45 & Piping Upstream of Check Valve & Cool & - \\
\hline
\end{tabular}


Table 3.1 Risk Importance AFW System 'Nalkdown Table

\begin{tabular}{llll}
\hline Component \# & Component Name & Required Location & $\begin{array}{l}\text { Actual } \\
\text { Position }\end{array}$ \\
\hline CA-49 & Piping Upstream of Check Valve & Cool & - \\
CA-53 & Piping Upstream of Check Valve & Cool & - \\
CA-57 & Piping Upstream of Check Valve & Cool & - \\
CA-61 & Piping Upstream of Check Valve & Cool & - \\
CA-65 & Piping Upstream of Check Valve & Cool
\end{tabular}




\section{Generic Risk Insights from PRAs}

PRAs for 13 PWRs were analyzed to identify riskimportant accident sequences involving loss of AFW, to identify and risk-prioritize the component failure modes involved. The results of this analysis are described in this section. They are consistent with results reported by INEL and BNL (Gregg et al 1988, and Travis et al, 1988).

\subsection{Risk Important Accident Sequences Involving AFW System Failure}

\section{Loss of Power System}

- A loss of offsite power is followed by failure of AFW. Due to lack of actuating power, the power operated relief valves (PORVs) cannot be opened preventing adequate feed-and-bleed cooling, and resulting in core damage.

- A station blackout fails all AC power except Vital AC from DC invertors, and all decay heat removal systems except the turbine-driven AFW pump. AFW subsequently fails due to battery depletion or hardware failures, resulting in core damage.

- $\quad$ A DC bus fails, causing a trip and failure of the power conversion system (PCS). One AFW motordriven pump is failed by the bus loss, AFW is subsequently lost completely due to other failures. Feedand-bleed cooling fails, resulting in core damage.

\section{Transient-Caused Reactor or Turbine Trip}

- A transient-caused trip is followed by a loss of the PCS and AFW. Feed-and-bleed cooling fails either due to failure of the operator to initiate it, or due to hardware failures, resulting in core damage.

\section{Loss of Main Feedwater}

- A feedwater line break drains the common water source for MFW and AFW. The operators fail to provide feedwater from other sources, and fail to initiate feed-and-bleed cooling, resulting in core damage.

- A loss of main feedwater trips the plant, and AFW fails due to operator error and hardware failures. The operators fail to initiate feed-and-bleed cooling, resulting in core damage.

\section{Steam Generator Tube Rupture (SGTR)}

- $\quad$ A SGTR is followed by failure of AFW. Coolant is lost from the primary until the refueling water storage tank (RWST) is depleted. High pressure injection (HPI) fails since recirculation cannot be established from the empty sump, and core damage results.

\subsection{Risk Important Component Failure Modes}

The generic component failure modes identified from PRA analyses as important to AFW system failure are listed below in decreasing order of risk importance.

1. Turbine-Driven Pump Failure to Start or Run.

2. Motor-Driven Pump Failure to Start or Run.

3. TDP or MDP Unavailable due to Test or Maintenance.

4. AFW System Valve Failures

- $\quad$ steam admission valves 
- trip and throttle valves

- flow control valves

- pump discharge valves

- pump suction valves

- valves in testing or maintenance.

5. Supply/Suction Sources

- condensate storage tank stop valve

- hot well inventory

- suction valves.
In addition to individual hardware, circuit, or instrument failures, each of these failure modes may result from common causes and human errors. Common cause failures of AFW pumps are particularly risk important. Valve failures are somewhat less important due to the multiplicity of steam generators and connection paths. Human errors of greatest risk importance involve: failures to initiate or control system operation when required; failure to restore proper system lineup after maintenance or testing; failure to verify operability after maintenance via post maintenance testing; and failure to switch to alternate sources when required. 


\section{Failure Modes Determined from Operating Experience}

This section describes the primary root cause of AFW system component failures, as determined from a review of operating histories at McGuire and at other PWRs throughout the nuclear industry. Section 5.1 describes experienze at McGuire. Section 5.2 summarizes information compiled from a variety of NRC sources, including AEOD analyses and reports, information notices, inspection and enforceme $\leadsto$ bulletins, and generic letters, and from a variety of INPO reports as well. Some Licensee Event Reports and NPRDS event descriptions were also reviewed. Finally, information was included from reports of NRC-sponsored studies of the effects of plant aging, which include quantitative analysis of AFW system failure reports. This information was used to identify the various root causes expected for the broad PRA-based failure events identified in Section 4.0, resulting in the inspection guidelines presented in Section 3.0.

\subsection{McGuire Experience}

The AFW system at McGuire has experienced failures of the AFW pumps, pump flow control and discharge isolation valves, turbine trip and throttle valves, and nuclear service water backup supply valves, and numerous system check valves. Failure modes include electrical, instrumentation and control, hardware failures, and human errors.

\subsubsection{Multiple Pump Failures}

There has been one incident where difficulty in control of the AFW system caused an abnormally fast cooldown rate. There were three other incidents where the shorting of an electrical lead or removal of the wrong wire caused multiple pump failures.

\subsubsection{Motor Driven Pump Failures}

There have been seven events since 1981 that have resulted in failure of individual motor driven pumps. Failures were caused by control circuit problems, open breakers, and incorrect procedures.

\subsubsection{Turbine Driven Pump Failures}

Eight events have occurred since 1981 that have resulted in decreased operational readiness or spurious starting of the turbine driven pump. Failure modes involved failures in instrumentation and control circuits, pump hardware failures, corrosion, mechanical wear, and human failures during maintenance activities. Improper or inadequate maintenance has resulted in high outboard bearing temperatures requiring pump shutdown and repair. Check valve leakage has also resulted in pump reverse rotation.

\subsubsection{Flow Control and Isolation Valve Failures}

Approximately a hundred events since 1981 have resulted in impaired operational readiness of the air and motor operated flow control valves, and motor operated isolation valves. Principal failure causes were equipment wear, corrosion, instrumentation and control circuit failures, valve hardware failures, and human errors. Valves have failed to operate properly due to blown fuses, failure of control components (such as I/P convertors), broken or dirty contacts, misaligned or broken limit switches, control power loss, and operator calibration problems. Human errors have resulted in improper: control circuit calibration, limit switch adjustment, installation of seals and meter reassembly.

\subsubsection{Check Valve Failures}

More than twenty events of check valve failure have occurred since 1981 . The predominant failure mode cited was normal wear and aging, however, abnormal stress resulting from inadequate design application was cited as the cause for check valve failure in several instances.

\subsubsection{Human Errors}

There have been approximately twenty events affecting the AFW system since 1985. Personnel have inadver-tently actuated the AFW pumps during testing, initiated 
AFW pump suction swapover to nuclear service water, mispositioned control switches during operation, and provided improper maintenance. Both personnel error and inadequate procedures have been involved. Misunderstanding of operability requirements has resulted in equipment exceeding Technical Specification limits.

\subsection{Industry Wide Experience}

Human errors, design/engineering problems and errors, and component failures are the primary root causes of AFW System failures identified in a review of industry wide system operating history. Common cause failures, which disable more than one train of this operationally redundant system, are highly risk significant, and can result from all of these causes.

This section identifies important common cause failure modes, and then provides a broader discussion of the single failure effects of human errors, design/engineering problems and errors, and component failures. Paragraphs presenting details of these failure modes are coded (e.g., $\mathrm{CC} 1$ ) and cross-referenced by inspection items in Section 3.

\subsubsection{Common Cause Failures}

The dominant cause of AFW system multiple-train failures has been human error. Design/engineering errors and component failures have been less frequent, but nevertheless significant, causes of multiple train failures.

$\mathrm{CCl}$. Human error in the form of incorrect operator intervention into automatic AFW system functioning during transients resulted in the temporary loss of all safety-grade AFW pumps during events at Davis Besse (NUREG-1154, 1985) and Trojan (AEOD/T416, 1983). In the Davis Besse event, improper manual initiation of the steam and feedwater rupture control system (SFRCS) led to overspeed tripping of both turbine-driven AFW pumps, probably due to the introduction of condensate into the AFW turbines from the long, unheated steam supply lines. (The system had never been tested with the abnormal, cross-connected steam supply lineup which resulted.) In the Trojan event the operator incorrectly stopped both AFW pumps due to misinterpretation of MFW pump speed indication. The diesel driven pump would not restart due to a protective feature requiring complete shutdown, and the turbine-driven pump tripped on overspeed, requiring local reset of the trip and throttle valve. In cases where manual intervention is required during the early stages of a transient, training should emphasize that actions should be performed methodically and deliberately to guard against such errors.

CC2. Valve mispositioning has accounted for a significant fraction of the human errors failing multiple trains of AFW. This includes closure of normally open suction valves or steam supply valves, and of isolation valves to sensors having control functions. Incorrect handswitch positioning and inadequate temporary wiring changes have also prevented automatic starts of multiple pumps. Factors identificd in studies of mispositioning errors include failure to add newly installed valves to valve checklists, weak administrative control of tagging, restoration, independent verification, and locked valve logging, and inadequate adherence to procedures. Illegible or confusing local valve labeling, and insufficient training in the determination of valve position may cause or mask mispositioning, and surveillance which does not exercise complete system functioning may not reveal mispositionings.

CC3. At ANO-2, both AFW pumps lost suction due to steam binding when they were lined up to both the CST and the hot startup/blowdown demineralizer effluent (AEOD/C404, 1984). At Zion-1 steam created by running the turbine-driven pump deadheaded for one minute caused trip of a motor-driven pump sharing the same inlet header, as well as damage to the turbine-driven pump (Region 3 Morning Report, 1/17/90). Both events were caused by procedural inadequacies.

CC4. Design/engineering errors have accounted for a smaller, but significant fraction of common cause failures. Problems with control circuit design modifications at Farley defeated AFW pump auto-start on loss of main feedwater. At Zion-2, restart of both motor driven pumps was blocked by circuit failure to deenergize when the pumps had been tripped with an automatic start signal present (IN 82-01, 1982). In addition, AFW control circuit design reviews at Salem and Indian Point have identified designs where failures of a single component could have failed all or multiple pumps (IN 87-34, 1987). 
CC5. Incorrect setpoints and control circuit settings resulting from analysis errors and failures to update procedures have also prevented pump start and caused pumps to trip spuriously. Errors of this type may remain undetected despite surveillance testing, unless surveillance tests model all types of system initiation and operating conditions. A greater fraction of instrumentation and control circuit problems has been identified during actual system operation (as opposed to surveillance testing) than for other types of failures.

CC6. On two occasions at a foreign plant, failure of a balance-of-plant inverter caused failure of two AFW pumps. In addition to loss of the motor driven pump whose auxiliary start relay was powered by the invertor, the turbine driven pump tripped on overspeed because the governor valve opened, allowing full steam flow to the turbine. This illustrates the importance of assessing the effects of failures of balance of plant equipment which supports the operation of critical components. The instrument air system is another example of such a system.

CC7. Multiple AFW pump trips have occurred at Millstone-3, Cook-1, Trojan and Zion-2 (IN 87-53, 1987) caused by brief, low pressure oscillations of suction pressure during pump startup. These oscillations occurred despite the availability of adequate static NPSH. Corrective actions taken include: extending the time delay associated with the low pressure trip, removing the trip, and replacing the trip with an alarm and operator action.

CC8. Design errors discovered during AFW system reanalysis at the Robinson plant (IN 89-30, 1989) and at Millstone-1 resulted in the supply header from the CST being too small to provide adequate NPSH to the pumps if more than one of the three pumps were operating at rated flow conditions. This could lead to multiple pump failure due to cavitation. Subsequent reviews at Robinson identified a loss of feedwater transient in which inadequate NPSH and flows less than design values had occurred, but which were not recognized at the time. Event analysis and equipment trending, as well as surveillance testing which duplicates service conditions as much as is practical, can help identify such design errors.

CC9. Asiatic clams caused failure of two AFW flow control valves at Catawba-2 when low suction pressure caused by starting of a motor-driven pump caused suction source realignment to the Nuclear Service Water system.
Pipes had not been routinely treated to inhibit clam growth, nor regularly monitored to detect their presence, and no strainers were installed. The need for surveillance which exercises alternative system operational modes, as well as complete system functioning, is emphasized by this event. Spurious suction switchover has also occurred at Callaway and at McGuire, although no failures resulted.

CC10. Common cause failures have also been caused by component failures (AEOD/C404, 1984). At Surry-2, both the turbine driven pump and one motor driven pump were declared inoperable due to steam binding caused by backleakage of hot water through multiple check valves. At Robinson-2 both motor driven pumps were found to be hot, and both motor and steam driven pumps were found to be inoperable at different times. Check valve leakage at Robinson-2 passed through closed motor-operated isolation valves in addition to multiple check valves. At Farley, both motor and turbine driven pump casings were found hot, although the pumps were not declared inoperable. In addition to multi-train failures, numerous incidents of single train failures have occurred, resulting in the designation of "Steam Binding of Auxiliary Feedwater Pumps" as Generic Issue 93. This generic issue was resolved by Generic Letter 88-03 (Miraglia, 1988), which required licensees to monitor AFW piping temperatures each shift, and to maintain procedures for recognizing steam binding and for restoring system operability.

CC11. Common cause failures have also failed motor operated valves. During the total loss of feedwater event at Davis Besse, the normally-open AFW isolation valves failed to open after they were inadvertently closed. The failure was due to improper setting of the torque switch bypass switch, which prevents motor trip on the high torque required to unseat a closed valve. Previous problems with these valves had been addressed by increasing the torque switch trip setpoint - a fix which failed during the event due to the higher torque required due to high differential pressure across the valve. Similar common mode failures of MOVs have also occurred in other systems, resulting in issuance of Generic Letter 89-10, "Safety Related Motor-Operated Valve Testing and Surveillance (Partlow, 1989)." This generic letter requires licensees to develop and implement a program to provide ior the testing, inspection and maintenance of all safetyrelated MOVs to provide assurance that they will function when subjected to design basis conditions. 
$\mathrm{CC12}$. Other component failures have also resulted in AFW multi-train failures. These include out-of-adjustment electrical flow controllers resulting in improper discharge valve operation, and a failure of oil cooler cooling water supply valves to open due to silt accumulation.

\subsubsection{Human Errors}

HE1. The overwhelmingly dominant cause of problems identified during a series of operational readiness evaluations of AFW systems was human performance. The majority of these human performance problems resulted from incomplete and incorrect procedures, particularly with respect to valve lineup information. A study of valve mispositioning events involving human error identified failures in administrative control of tagging and logging, procedural compliance and completion of steps, verification of support systems, and inadequate procedures as important. Another study found that valve mispositioning events occurred most often during maintenance, calibration, or modification activities. Insufficient training in determining valve position, and in administrative requirements for controlling valve positioning were important causes, as was oral task assignment without task completion feedback.

HE2. Turbine driven pump failures have been caused by human errors in calibrating or adjusting governor speed control, poor governor maintenance, incorrect adjustment of governor valve and overspeed trip linkages, and errors associated with the trip and throttle valve. TTV-

associated errors include physically bumping it, failure to restore it to the correct position after testing, and failures to verify control room indication of TTV position following actuation.

HE3. Motor driven pumps have been failed by human errors in mispositioning handswitches, and by procedure deficiencies.

\subsubsection{Design/Engineering Problems and Errors}

DE1. As noted above, the majority of AFW subsystem failures, and the greatest relative system degradation, has been found to result from turbine-driven pump failures. Overspeed trips of Terry turbines controlled by Woodward governors have been a significant source of these failures (AEOD/C602, 1986). In many cases these overspeed trips have been caused by slow response of a Woodward Model EG governor on startup, at plants where full steam flow is allowed immediately. This oversensitivity has been removed by installing a startup steam bypass valve which opens first, allowing a controlled turbine acceleration and buildup of oil pressure to control the governor valve when full steam flow is admitted.

DE2. Overspeed trips of Terry turbines have been caused by condensate in the steam supply lines. Condensate slows down the turbine, causing the governor valve to open farther, and overspeed results before the governor valve can respond, after the water slug clears. This was determined to be the cause of the loss-of-all-AFW event at Davis Besse (AEOD/602, 1986), with condensation enhanced due to the long length of the cross-connected steam lines. Repeated tests following a cold-start trip may be successful due to system heat up.

DE3. Turbine trip and throttle valve (TTV) problems are a significant cause of turbine driven pump failures (IN 84-66). In some cases lack of TTV position indication in the control room prevented recognition of a tripped TTV. In other cases it was possible to reset either the overspeed trip or the TTV without resetting the other. This problem is compounded by the fact that the position of the overspeed trip linkage can be misleading, and the mechanism may lack labels indicating when it is in the tripped position (AEOD/C602, 1986).

DE4. Startup of turbines with Woodward Model PG-PL governors within 30 minutes of shutdown has resulted in overspeed trips when the speed setting knob was not exercised locally to drain oil from the speed setting cylinder. Speed control is based on startup with an empty cylinder. Problems have involved turbine rotation due to both procedure violations and leaking steam. Terry has marketed two types of dump valves for automatically draining the oil after shutdown (AEOD/C602, 1986).

At Calvert Cliffs, a 1987 loss-of-offsite-power event required a quick, cold startup that resulted in turbine trip due to PG-PL governor stability problems. The shortterm corrective action was installation of stiffer buffer springs (IN 88-09, 1988). Surveillance had always been preceded by turbine warmup, which illustrates the importance of testing which duplicates service conditions as much as is practical. 
Failure Modes

DE5. Reduced viscosity of gear box oil heated by prior operation caused failure of a motor driven pump to start due to insufficient lube oil pressure. Lowering the pressure switch setpoint solved the problem, which had not been detected during testing.

DE6. Waterhammer at Palisades resulted in AFW line and hanger damage at both steam generators. The AFW spargers are located at the normal steam generator level, and are frequently covered and uncovered during level fluctuations. Waterhammers in top-feed-ring steam generators resulted in main feedline rupture at Maine Yankee and feedwater pipe cracking at Indian Point-2 (IN 84-32, 1984).

DE7. Manually reversing the direction of motion of an operating valve has resulted in MOV failures where such loading was not considered in the design (AEOD/C603, 1986). Control circuit design may prevent this, requiring stroke completion before reversal.

DE8. At each of the units of the South Texas Project, space heaters provided by the vendor for use in preinstallation storage of MOVs were found to be wired in parallel to the Class 1E $125 \mathrm{~V} \mathrm{DC}$ motors for several AFW valves (IR 50-489/89-11; 50-499/89-11, 1989). The valves had been environmentally qualified, but not with the non-safety-related heaters energized.

\subsubsection{Component Failures}

Generic Issue II.E.6.1, "In Situ Testing Of Valves" was divided into four sub-issues (Beckjord, 1989), three of which relate directly to prevention of AFW system component failure. At the request of the NRC, in-situ testing of check valves was addressed by the nuclear industry, resulting in the EPRI report, "Application Guidelines for Check Valves in Nuclear Power Plants (Brooks, 1988)." This extensive report provides information on check valve applications, limitations, and inspection techniques. In-situ testing of MOVs was addressed by Generic Letter 89-10, "Safety Related Motor-Operated Valve Testing and Surveillance" (Partlow, 1989) which requires licensees to develop and implement a program for testing, inspection and maintenance of all safety-related MOVs. "Thermal Overload Protection for Electric Motors on Safety-Related Motor-Operated Valves - Generic Issue II.E.6.1 (Rothberg, 1988)" concludes that valve motors should be thermally protected, yet in a way which emphasizes system function over protection of the operator.

CF1. The common-cause steam binding effects of check valve leakage were identified in Section 5.2.1, entry CC10. Numerous single-train events provide additional insights into this problem. In some cases leakage of hot MFW past multiple check valves in series has occurred because adequate valve-seating pressure was limited to the valves closest to the steam generators (AEOD/C404, 1984). At Robinson, the pump shutdown procedure was changed to delay closing the MOVs until after the check valves were seated. At Farley, check valves were changed from swing type to lift type. Check valve rework has been done at a number of plants. Different valve designs and manufacturers are involved in this problem, and recurring leakage has been experienced, even after repair and replacement.

CF2. At Robinson, heating of motor operated valves by check valve leakage has caused thermal binding and failure of AFW discharge valves to open on demand. At Davis Besse, high differential pressure across AFW injection valves resulting from check valve leakage has prevented MOV operation (AEOD/C603, 1986).

CF3. Gross check valve leakage at McGuire and Robinson caused overpressurization of the AFW suction piping. At a foreign PWR it resulted in a severe waterhammer event. At Palo Verde-2 the MFW suction piping was overpressurized by check valve leakage from the AFW system (AEOD/C404, 1984). Gross check valve leakage through idle pumps represents a potential diversion of AFW pump flow.

CF4. Roughly one third of AFW system failures have been due to valve operator failures, with about equal failures for MOVs and AOVs. Almost half of the MOV failures were due to motor or switch failures (Casada, 1989). An extensive study of MOV events (AEOD/C603, 1986) indicates continuing inoperability problems caused by: torque switch/limit switch settings, adjustments, or failures; motor burnout; improper sizing or use of thermal overload devices; premature degradation related to inadequate use of protective devices; damage due to misuse (valve throttling, valve operator hammering); mechanical problems (loosened parts, improper assernbly); or the torque switch bypass circuit improperly installed or 
adjusted. The study concluded that current methods and procedures at many plants are not adequate to ensure that MOVs will operate when needed under credible accident conditions. Specifically, a surveillance test which the valve passed might result in undetected valve inoperability due to component failure (motor burnout, operator parts failure, stem disc separation) or improper positioning of protective devices (thermal overload, torque switch, limit switch). Generic Letter 89-10 (Partlow, 1989) has subsequently required licensees to implement a program ensuring that MOV switch settings are maintained so that the valves will operate under design basis conditions for the life of the plant.

CF5. Component problems have caused a significant number of turbine driven pump trips (AEOD/C602, 1986). One group of events involved worn tappet nut faces, loose cable connections, loosened set screws, improperly latched TTVs, and improper assembly. Another involved oil leaks due to component or seal failures, and oil contamination due to poor maintenance activities. Governor oil may not be shared with turbine lubrication oil, resulting in the need for separate oil changes. Electrical component failures included transistor or resistor failures due to moisture intrusion, erroneous grounds and connections, diode failures, and a faulty circuit card.

CF6. Electrohydraulic-operated discharge valves have performed very poorly, and three of the five units using them have removed them due to recurrent failures. Failures included oil leaks, contaminated oil, and hydraulic pump failures.

CF7. Control circuit failures were the dominant source of motor driven AFW pump failures (Casada, 1989). This includes the controls used for automatic and manual starting of the pumps, as opposed to the instrumentation inputs. Most of the remaining problems were due to circuit breaker failures.

CF8. "Hydraulic lockup" of Limitorque SMB spring packs has prevented proper spring compression to actuate the MOV torque switch, due to grease trapped in the spring pack. During a surveillance at Trojan, failure of the torque switch to trip the TTV motor resulted in tripping of the thermal overload device, leaving the turbine driven pump inoperable for $\mathbf{4 0}$ days until the next surveillance (AEOD/E702, 1987). Problems result from grease changes to EXXON NEBULA EP-0 grease, one of only two greases considered environmentally qualified by Limiitorque. Due to lower viscosity, it slowly migrates from the gear case into the spring pack. Grease changeover at Vermont Yankee affected 40 of the older MOVs of which 32 were safety related. Grease relief kits are needed for MOV operators manufactured before 1975. At Limerick, additional grease relief was required for MOVs manufactured since 1975. MOV refurbishment programs may yield other changeovers to EP-0 grease.

CF9. For AFW systems using air operated valves, almost half of the system degradation has resulted from failures of the valve controller circuit and its instrument inputs (Casada, 1989). Failures occurred predominantly at a few units using automatic electronic controllers for the flow control valves, with the majority of failures due to electrical hardware. At Turkey Point-3, controller malfunction resulted from water in the Instrument Air system due to maintenance inoperability of the air dryers.

CF10. For systems using diesel driven pumps, most of the failures were due to start control and governor speed control circuitry. Half of these occurred on demand, as opposed to during testing (Casada, 1989).

CF11. For systems using AOVs, operability requires the availability of Instrument Air, backup air, or backup nitrogen. However, NRC Maintenance Team Inspections have identified inadequate testing of check valves isolating the safety-related portion of the IA system at several utilities (Letter, Roe to Richardson). Generic Letter 88-14 (Miraglia, 1988), requires licensees to verify by test that air-operated safety-related components will perform as expected in accordance with all design-basis events, including a loss of normal IA. 


\section{References}

Beckjord, E. S. June 30, 1989. Closeout of Generic Issue II.E.6.I, "In Situ Testing of Valves". Letter to V. Stello, Jr., U.S. Nuclear Regulatory Commission, Washington, DC.

Brooks, B. P. 1988. Application Guidelines for Check Valves in Nuclear Power Plants. NP-5479, Electric Power Research Institute, Palo Alto, CA.

Casada, D. A. 1989. Auxiliary Feedwater System Aging Study. Volume 1. Operating Experience and Current Monitoring Practices. NUREG/CR-5404. U.S. Nuclear Regulatory Commission, Washington, DC.

Gregg, R. E. and R. E. Wright. 1988. Appendix Review for Dominant Generic Contributors. BLB-31-88. Idaho National Engineering Laboratory, Idaho Falls, Idaho.

Miraglia, F. J. February 17, 1988. Resolution of Generic Safety Issue 93, "Steam Binding of Auxiliary Feedwater Pumps" (Generic Letter 88-03). U.S. Nuclear Regulatory Commission, Washington, DC.

Miraglia, F. J. August 8, 1988. Instrument Air Supply System Problems Affecting Safety-Related Equipment (Generic Letter 88-14). U.S. Nuclear Regulatory Commission, Washington, DC.

Partlow, J. G. June 28, 1989. Safety-Related MotorOperated Valve Testing and Surveillance (Generic Letter 89-10). U.S. Nuclear Regulatory Commission, Washington, DC.

Rothberg, O. June 1988. Thermal Overload Protection for Electric Motors on Safety-Related Motor-Operated Valves - Generic Issue II.E.6.1. NUREG-1296. U.S. Nuclear Regulatory Commission, Washington, DC.

Travis, R. and J. Taylor. 1989. Development of Guidance for Generic, Functionally Oriented PRA-Based Team Inspections for BWR Plants-Identification of RiskImportant Systems, Components and Human Actions. TLR-A-3874-TGA Brookhaven National Laboratory, Upton, New York.

\section{AEOD Reports}

AEOD/C404. W. D. Lanning. July 1984. Steam Binding of Auxiliary Feedwater Pumps. U.S. Nuclear Regulatory Commission, Washington, DC.

AEOD/C602. C. Hsu. August 1986. Operational Experience Involving Turbine Overspeed Trips. U.S. Nuclear Regulatory Commission, Washington, DC.

AEOD/C603. E. J. Brown. December 1986. A Review of Motor-Operated Valve Performance. U.S. Nuclear Regulatory Commission, Washington, DC.

AEOD/E702. E. J. Brown. March 19, 1987. MOV Failure Due to Hydraulic Lockup From Excessive Grease in Spring Pack. U.S. Nuclear Regulatory Commission, Washington, DC.

AEOD/T416. January 22, 1983. Loss of ESF Auxiliary Feedwater Pump Capability at Trojan on January 22, 1983. U.S. Nuclear Regulatory Commission, Washington, DC.

\section{Information Notices}

IN 82-01. January 22, 1982. Auxiliary Feedwater Pump Lockout Resulting from Westinghouse W-2 Switch Circuit Modification. U.S. Nuclear Regulatory Commission, Washington, DC.

IN 84-32. E. L. Jordan. April 18, 1984. Auxiliary Feedwater Sparger and Pipe Hangar Damage. U.S. Nuclear Regulatory Commission, Washington, DC.

IN 84-66. August 17, 1984. Undetected Unavailability of the Turbine-Driven Auxiliary Feedwater Train. U.S. Nuclear Regulatory Commission, Washington, DC.

IN 87-34. C. E. Rossi. July 24, 1987. Single Failures in Auxiliary Feedwater Systems. U.S. Nuclear Regulatory Commission, Washington, DC. 
IN 87-53. C. E. Rossi. October 20, 1987. Auxiliary Feedwater Pump Trips Resulting from Low Suction Pressure. U.S. Nuclear Regulatory Commission, Washington, DC.

IN 88-09. C. E. Rossi. March 18, 1988. Reduced Reliability of Steam-Driven Auxiliary Feedwater Pumps Caused by Instability of Woodward PG-PL Type Governors. U.S. Nuclear Regulatory Commission, Washington, DC.

IN 89-30. R. A. Azua. August 16, 1989. Robinson Unit 2 Inadequate NPSH of Auxiliary Feedwater Pumps. Also, Event Notification 16375, August 22, 1989. U.S.

Nuclear Regulatory Commission, Washington, DC.

\section{Inspection Report}

IR 50-489/89-11; 50-499/89-11. May 26, 1989. South Texas Project Inspection Report. U.S. Nuclear Regulatory Commission, Washington, DC.

\section{NUREG Report}

NUREG-1154. 1985. Loss of Main and Auxiliary Feedwater Event at the Davis Besse Plant on June 9, 1985. U.S. Nuclear Regulatory Commission, Washington, DC. 


\section{Distribution}

No. of

Copies

\section{OFFSITE}

\section{U.S. Nuclear Regulatory Commission}

B. K. Grimes OWFN 9 A2

F. Congel

OWFN 10 E4

G. M. Holahan

OWFN 8 E2

A. C. Thadani

OWFN 8 E2

W. T. Russell

OWFN 12 G18

\section{K. Campe}

OWFN 1 A2

10 J. Chung

OWFN 10 A2

2 B. Thomas

OWFN 12 H26

U.S. Nuclear Regulatory Commission Region 2

S. D. Ebneter

A. F. Gibson

K. D. Landis

L. A. Reyes

$4 \quad$ McGuire Resident Inspector Office

J. H. Taylor

Brookhaven National Laboratory

Bldg. 130

Upton, NY 11973
No. of

Copies

R. Travis

Brookhaven National Laboratory

Bldg. 130

Upton, NY 11973

J. Bickel

EG\&G Idaho, Inc.

P.O. Box 1625

Idaho Falls, ID 83415

Dr. D. R. Edwards

Professor of Nuclear Engineering

University of Missouri - Rolla

Rolla, MO 65401

\section{ONSITE}

$18 \quad$ Pacific Northwest Laboratory

J. D. Bumgardner

L. R. Dodd

B. F. Gore (5)

R. C. Lloyd

N. E. Moffitt

B. D. Shipp

F. A. Simonen

T. V. Vo

Publishing Coordination

Technical Report File (5) 

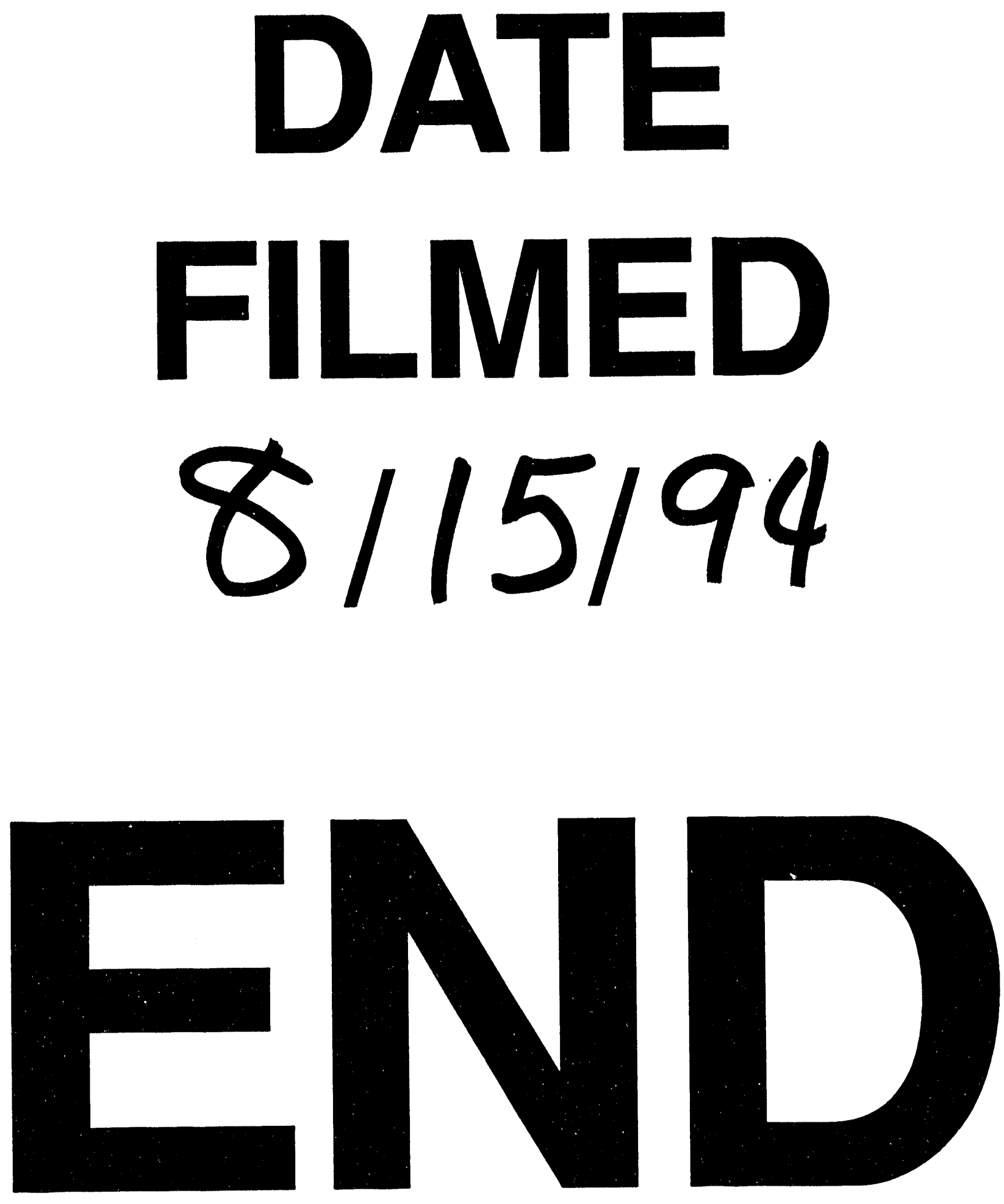


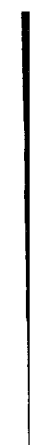

